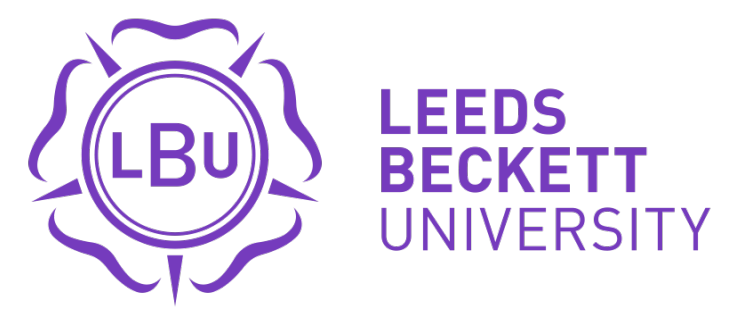

Citation:

Woodall, $\mathrm{J}$ and de Viggiani, N and Dixey, R and South, J (2014) Moving prison health promotion along: Towards an integrative framework for action to develop health promotion and tackle the social determinants of health. Criminal Justice Studies, 27 (1). 114 - 132. ISSN 1478-601X DOI: https://doi.org/10.1080/1478601X.2013.873208

Link to Leeds Beckett Repository record:

https://eprints.leedsbeckett.ac.uk/id/eprint/91/

Document Version:

Article (Accepted Version)

The aim of the Leeds Beckett Repository is to provide open access to our research, as required by funder policies and permitted by publishers and copyright law.

The Leeds Beckett repository holds a wide range of publications, each of which has been checked for copyright and the relevant embargo period has been applied by the Research Services team.

We operate on a standard take-down policy. If you are the author or publisher of an output and you would like it removed from the repository, please contact us and we will investigate on a case-by-case basis.

Each thesis in the repository has been cleared where necessary by the author for third party copyright. If you would like a thesis to be removed from the repository or believe there is an issue with copyright, please contact us on openaccess@leedsbeckett.ac.uk and we will investigate on a case-by-case basis. 


\title{
Moving prison health promotion along: toward an integrative framework for action to develop health promotion and tackle the social determinants of health
}

\begin{abstract}
The majority of prisoners are drawn from deprived circumstances with a range of health and social needs. The current focus within 'prison health' does not, and cannot, given its predominant medical model, adequately address the current health and wellbeing needs of offenders. Adopting a social model of health is more likely to address the wide range of health issues faced by offenders and thus lead to better rehabilitation outcomes. At the same time, broader action at governmental level is required to address the social determinants of health (poverty, unemployment, educational attainment) that marginalise populations and increase the likelihood of criminal activities. Within prison, there is more that can be done to promote prisoners' health if a move away from a solely curative, medical model is facilitated, towards a preventive perspective designed to promote positive health. Here we use the Ottawa Charter for health promotion to frame public health and health promotion within prisons and to set out a challenging agenda that would make health a priority for everyone, not just 'health' staff, within the prison setting. A series of outcomes under each of the five action areas of the Charter offers a plan of action, showing how each can improve health. We also go further than the Ottawa Charter, to comment on how the values of emancipatory health promotion need to permeate prison health discourse, along with the concept of salutogenesis.
\end{abstract}

Keywords Prison health, public health, health promotion, Ottawa Charter, social determinants. 


\section{Context}

There is now a wealth of evidence that demonstrates that people in prison face a disproportionate burden of health and social inequality. Many diseases, illnesses and longterm conditions are over-represented in prison populations and disadvantaged social circumstances are commonplace for most of those imprisoned. For these reasons, some have argued that public health and health promotion in the prison population is as much, if not more, significant than efforts in the 'free' community (Ross, 2013); yet, the concept and practice of public health and health promotion in prison is both contested and underdeveloped with significant variation in its application in prison systems globally. This paper outlines what the authors regard as 'prison health' and what the determinants of prison health are. Our argument is that a social model of health in prison has not been taken far enough, and that and an appreciation of the wider social determinants of health has not been fully addressed in terms of policy responses. Our view stands in stark contrast to the 'bounded' medical model which usually prevails in prison health systems, and that regards health as being an absence of disease. The paper explores whether our understanding of a social model of prison health can lead to a workable framework to develop policy and practice for public health and health promotion in prison. Moreover, we suggest how this framework may be measured and what may constitute successful outcomes. We do not claim to provide startlingly new contributions, but we do wish to move the health promoting prison agenda along by re-igniting debate. Thus we also discuss how the determinants of health agenda can be developed into one concerned with the social determination of health - that is health being determined by 'the people'. Prisons do not enable prisoners to take control of the factors governing their health, and where health promotion has been developed, it tends to be within a medical model of health promotion, focussing on individual lifestyle 'choices'. Examples 
are where education about alcohol or drugs is provided, without full understanding of the social context or of enabling offenders to develop skills in avoiding substance misuse on the outside or inside. Further, given the reoffending rates, prisons are not rehabilitative institutions and the criminal justice system as it operates appears unable to tackle the social conditions that lead to initial offending or reoffending.

\section{The contribution of the World Health Organisation (WHO)}

It is important to discuss the contribution to date made to public health and health promotion in prison by the WHO, as their strategic oversight has been a salient factor in ensuring that prison health is on the public health agenda of various nations (Gatherer, Møller, \& Hayton, 2005). We offer this as a brief overview to those who may not be aware of efforts in this area to date.

The work developed by WHO Europe has been particularly prominent (Møller, Gatherer, \& Dara, 2009; Møller, Stöver, Jürgens, Gatherer, \& Nikogosian, 2007) and is seen as a model to enable global expansion. The American Public Health Association's (APHA) human rights committee, for example, is working to bring the lessons learned from successful European prison health initiatives to the Americas (Anon, 2008). Designated work in other WHO regions is less apparent and tends to 'lag' behind policy developments in Europe. This is not to say that public health and health promotion work is not present in these regions, rather it is not co-ordinated as clearly under the WHO banner. Current guidance from the WHO suggests that the health promoting prison is underpinned by four key pillars and grounded in a 'settings approach' - the premise of which is that investments in health are made in social institutions whose primary remit is not health (Dooris, 2007). These four key pillars 
acknowledge that prisons should be: safe; secure; reforming and health promoting; and grounded in the concept of decency and respect for human rights (Hayton, 2007). Equivalence is a further principle that informs public health efforts in prison. The principle of 'equivalence' is based on the view that individuals detained in prison must have the benefit of care equivalent to that provided to the general public (Niveau, 2007). Critics have argued, however, that an equivalent health service in prison is an "insufficient public health response"(Lines, 2006, p.276) given the extent of health and social inequalities.

The WHO has been active in publishing key documents and statements to shape global public health efforts in prison, including: 'Mental Health Promotion in Prisons' (WHO, 1998), 'HIV in Prisons' (WHO, 2001a), 'Prisons, Drugs and Society' (WHO, 2001b), 'Promoting the Health of Young People in Custody' (WHO, 2003) and a practical guide to the essentials in prison health (WHO, 2007). In 2005, Gatherer et al. (2005) appraised the progress made by the WHO in prisons and concluded that despite considerable achievements, formidable barriers remained including overcrowding and unhygienic facilities, rising prison populations, inherent traditions, political perspectives, the reluctance of staff to evolve their ways of working and resource restrictions. Indeed, whilst the concept of a health promoting prison seems laudable, prisons are not primarily geared to improving health (Smith, 2000). In short Awofeso (2010) lists the issues as:

1. The concentration of unhealthy individuals

2. The amplification of unhealthy behaviors

3. The deterioration of existing health conditions

4. The dissemination of infectious diseases, and

5. Post-release morbidity and mortality, resulting from health conditions developed or exacerbated during incarceration 
We would add that loss of freedom in itself is inherently pathogenic and whilst prisons have a duty of care to prisoners they also must place to the fore concerns with public safety and thus with prison security.

\section{What is prison health?}

While recognising that prisoners are not a homogenous group, epidemiological assessment of the population shows undeniable health need, with research evidence consistently demonstrating that the prevalence of ill health is higher than reported in the wider community (Senior \& Shaw, 2007). Mental health problems (Fazel \& Danesh, 2002; WHO, 2008), longstanding physical disorders (Plugge, Douglas, \& Fitzpatrick, 2006; Stewart, 2008) and drug and alcohol issues (Social Exclusion Unit, 2002; The Centre for Social Justice, 2009; Woodall, 2012) are commonplace. In addition to health problems, multifaceted social issues face the prison population which in turn impact on health (Rutherford \& Duggan, 2009; Stewart, 2008). Jacobs back in 1977 observed how the prison population was influenced by social trends and processes beyond the prison wall (Jacobs, 1977). Indeed, many of those entering the criminal justice system have experienced a lifetime of social exclusion, including poor educational backgrounds, low incomes, meagre employment opportunities, lack of engagement with normal societal structures, low self-esteem and impermanence in terms of accommodation (including bouts of homelessness) and relationships with family members (Department of Health, 2009; Levy, 2005; Prison Reform Trust, 2009; Senior \& Shaw, 2007; Social Exclusion Unit, 2002).

Developing clear strategies to address the health and social issues reported in the prison population relies on how health is defined. The concept of 'prison health' has, in the main, 
been clearly aligned to a biomedical perspective (Sim, 1990). Morris and Morris (1963, p.193), in their study of Pentonville prison, encapsulated the predominant discourse which surrounded prison health:

"For the prison, health is essentially a negative concept; if men are not ill, de facto they are healthy. While most modern thinking in the field of social medicine has attempted to go further than this, for the prison medical staff it is not an unreasonable operational definition."

In the American correctional system, the concept of health had been underpinned in a similar way. When the Medical Center for Federal Prisoners in Springfield was opened in 1933, it was "dedicated solely" to caring for the diseased and the "broken bodies and minds of offenders"'(Bosworth, 2002, p.79). Through this lens, health is conceptualised in a reductionist, rather than holistic, way and viewed in terms of pathology, disease, diagnosis and treatment (Warwick-Booth, Cross, \& Lowcock, 2012). This has notable implications, as health is defined by its absence of disease and not the attainment of positive health and wellbeing. Moreover, the medical model of health tends to focus on physical dimensions of health (such as physical fitness and functionality) rather than mental (such as having a sense of purpose and meaning) and social dimensions of health (such as feeling connected to the community).

Anno's (2004) comparative article reviewing US prison health services in the 1970s to the present, argues that while much has been done to improve health systems in prison the focus remains on addressing acute physical and mental medical need rather than addressing other dimensions of prisoners' health and well-being. Moreover, an international systematic review (which included studies from Australasia, Europe, US and Africa) conducted by Herbert and colleagues (2012) concluded that prison health services fail to fully exploit 
public health and 'upstream' health promotion work. This has been echoed in England and Wales where critical reviews of prison health services described a reactive and inefficient service, underpinned by a medical model that was largely blind to the social determinants of health and thus failed to exploit public health opportunities (HMIP, 1996).

There have been clear efforts in recent times to detach prison health services from the biomedical perspective (Department of Health, 2002; HM Prison Service, 2003) with US commentators like Winterbauer and Diduk (2013) arguing that public health efforts in prison have now evolved from simply disease-based models. Baybutt et al. (2010) have optimistically argued that the medical model of health provision has been reformed; however, the discourse surrounding health in prison keeps its heavy, unbalanced focus on disease control, eradication, screening and testing. In contrast, the social model sees ill-health as caused by social conditions and thus the solution lies in tackling those underlying social causes of poor health, including low levels of literacy, poor interpersonal skills, lack of employability skills, social exclusion and so on. This recognition of social factors remains side-lined in policy and practice discourse.

Previous research has raised questions about the definitions of health currently deployed in the prison environment and how 'normative' health need, i.e. that defined by expert/professional opinion, has governed much prison health policy and planning (Smith, 2002). Arguably, the social model of health encompasses 'lay' perspectives about health, taking into account subjective experience and understandings. Indeed, Robertson (2006) suggests that lay perceptions have been influential in supporting a cultural shift away from a biomedical perspective towards a more holistic and integrated understanding of health and well-being. Whilst research on prisoners' lay health views is scanty, it does demonstrate that 
factors such as access to the outdoors and social relationships, especially contact with family members, were intimately intertwined with prisoners' ideas around being healthy (Woodall, 2010b). Bosworth et al.(2005) have noted that it can be difficult, without serving a sentence, to know what prison life is like; yet, this understanding is vital if we are to address 'health' in a meaningful way. The extent that this broader understanding of 'health' and wellbeing can be incorporated into prison health strategy is debateable given the current concern overwhelmingly remaining with disease prevention and management rather than with an acknowledgement of the broader social determinants of health and of lay perspectives on what constitutes health.

\section{The determinants of prisoner health}

Public health and health promotion interventions within prison settings have been consistently criticised because they frequently focus on the symptoms of the problem rather than tackling the root causes of poor health, such as the social determinants of health (Caraher et al., 2002). Marquart et al's. (1997) conceptual framework for prison public health was a starting-point that usefully demonstrated the interaction of prisoners' pre-prison health conditions, the impact on health caused by admission to prison and the impact during

imprisonment. More recently, and drawing on a similar school of thought, de Viggiani (2006) has argued that both deprivation and importation factors are significant health determinants within prison. This framework delineates those factors caused by imprisonment that contribute to ill health (deprivation) and those which are a result of circumstances predating a custodial sentence (importation). Smith (2000) suggests that health problems experienced by prisoners are entrenched in their wider environment and their experience of inequality, poverty and disadvantage. She notes that public health attempts in prison contribute towards dealing with behaviour change, but it is only when the collective factors 
that produce ill-health (outside prison) are tackled will there be any real health improvement. This is reiterated by Caraher et al. (2002) who suggest that there is a need for health promotion in prison, but also for wider public policy which addresses the broader determinants of health and illness.

The imported nature of individuals' pre-existing health issues to the prison setting was inferred by Goffman (1968, p.12) who suggested that inmates come into the institution with a "presenting culture" derived from their "home world". In other words, an individual imports life experiences into the prison which may influence their health. As an example, $32 \%$ of the prison population are homeless prior to their incarceration and over two-thirds of prisoners are unemployed prior to imprisonment (Social Exclusion Unit, 2002). Both of these social circumstances are known to impact on physical, mental and social components of health. It can be argued, however, that prison itself is also harmful to health. Regardless of an individual's background prior to incarceration, the prison can inflict ill health onto those who are placed there through the deprivation of liberty. Gresham Sykes (1958) in his classic study of a maximum security prison, suggested that imprisonment itself was painful and that it deprived individuals not only of their physical liberty, but goods and services, heterosexual relationships, autonomy and security. These deprivations collectively threatened the prisoner's personality and sense of personal worth. As an example, cell confinement has a deleterious effect on health, particularly for those with pre-existing mental health issues (Shalev, 2008). As a further example, overcrowded prison systems have implications for the transmission of communicable disease and for potentially limiting prisoners' access to services and support due to low staff-prisoner ratios. Perhaps more implicit are the influences within prison that are clearly detrimental to all facets of a prisoner's health and well-being. As an example, studies show that many prisoners are motivated to stop smoking, 
but often increase the number of cigarettes they smoke in prison to cope with the 'suffocating boredom' of prison life (Belcher, Butler, Richmond, Wodak, \& Wilhelm, 2006; Lester, Hamilton-Kirkwood, \& Jones, 2003; Sim, 2002; P. Squires \& Measor, 2001). The literature also suggests that bullying (Edgar, O'Donnell, \& Martin, 2003; C. A. Ireland \& Ireland, 2000; J. L. Ireland, 2002), violence (Edgar, et al., 2003; Lahm, 2009; Reyes, 2001), homophobia (Gear, 2007; Hensley, 2000; Newton, 1994) and racism (Bhui, 2009; Spalek, 2002; Spencer, Haslewood-Pocsik, \& Smith, 2009) still remain in modern prison systems.

A persuasive argument is for a more integrative conceptual model, whereby a combination of the deprivations of prison life and importation of pre-prison circumstances contribute to prisoner health. However, in their current guise, prison policy remains focussed on individually centred lifestyle interventions or disease prevention activities and there remains an over-simplification of the determinants influencing prisoners' health. As an example, the English and Welsh Prison Services' strategy for promoting health focuses on smoking, healthy eating and nutrition and healthy lifestyle (HM Prison Service, 2003). In terms of addressing health, there is an overemphasis on individual behaviour to the exclusion of broader social and structural processes that are at work both in prison and wider society. Through this lens, poor health rests with the individual, with the prison setting simply functioning as a neutral vehicle offering favourable circumstances to undertake individually focussed health activities. We argue that a more radical, upstream and holistic outlook is required and we advocate for a shift away from a purely expedient view which considers the prison as a convenient venue for addressing the health lifestyles of offenders. The promulgation of health should be integral to the institution's culture and this includes considering architecture, policies, ethos, social structures, prisoner-staff relationships and how these impact on individuals. This suggests that enduring change can only reasonably 
happen when the emphasis moves away from individual behaviour to changes at social and structural levels (de Viggiani, 2007). Thus in tandem with the interventions within prison, action needs to be taken to address the deprived and pathogenic environments that the majority of prisoners were brought up in and to which they inevitably return upon release. This will require prisons to work more collaboratively with agencies in the community and while this poses challenges, they are not insurmountable as shown by Lincoln's (2007) discussion on collaborations across organisations working within and outside the prison system. Moreover, Visher and Travis (2003) argue that the research and academic community also need to target more efforts to understand how best to manage the prisoncommunity transition that offenders face.

\section{A prison health action and outcomes framework}

Our argument is that to address the health and social inequalities faced by the prison population, a broader social model of health and an appreciation of wider determinants is necessary. However, by adopting such a holistic philosophy it 'opens up' a range of possible influences on health and this can be challenging for policy-makers and for practitioners whose aim is that of public health improvement in prison settings. In short, can our understanding of a social model of prison health lead to a workable framework to develop policy and practice for the improved health of prisoners?

For the remainder of the paper we attempt to offer an overarching prison health action and outcomes framework to guide policy, practice and evaluation. This is particularly useful, given that there are few models which indicate how healthy prison settings can be achieved (Ross, 2013). Our framework is informed by the Ottawa Charter, an influential health 
promotion strategy document emerging in 1986, which indicated that 'health' is wider than 'healthcare' and that health education alone cannot bring about improved health (World Health Organization, 1986). The Charter attempts to address both structural forces that influence health (e.g. policy, environment) and also the individual health choices (agency) that people make (Rütten \& Gelius, 2011). The Charter provides five principal areas for action: building healthy public policy; creating supportive environments; strengthening community action; developing personal skills; re-orientating health services (WHO, 1986). These five areas have continued to provide a useful framework for the delivery of health promotion and public health programmes (Kickbusch, 2003) and authors claim that the Charter has had a "phenomenal influence" on the development of health promotion practice over the past two decades (Nutbeam, 2008, p.436). Despite this endorsement, the explicit application of the Charter to prison settings has been rarely considered (although see Ramaswamy \& Freudenberg, 2007; Woodall \& South, 2012).

Given the diversity of health issues in the prison setting we have applied each of the five principal areas for action within the Ottawa Charter. Moreover, we have attempted to capture some of potential outcomes and where possible, the links between changes in personal, social and environmental factors, intermediate health outcomes, such as health behaviours, and longer term health and social outcomes (Nutbeam, 1998).

\section{Building healthy public policy}

Building healthy public policy can be seen as the chief innovation of the Ottawa Charter, moving health promotion firmly away from an individual, lifestyle focus and towards those actions which could impact upon whole populations. No smoking policies, for example, or polices governing minimum nutritional standards for institutional food automatically create 
potential for healthier outcomes without individuals needing to decide to take healthier actions. Thus, Kemm (2001) argues that healthy public policy is any policy that increases the health and well-being of those individuals that it affects. Policy can occur at an institutional level within an organisation (e.g. prison) or at a macro level (e.g. national policy).

Certain policy at the institutional (prison) level can be at odds with the goals of healthy public policy. For example, being locked and confined within a prison cell can be detrimental to physical and mental health (Shalev, 2008; Woodall, 2010a). However, a goal should be that institutional policies are considered in relation to the impact on prisoners' health and should be designed to ensure that 'healthy choices are easier choices' (Kickbusch, 1986; Milio, 1986). As an example, condom availability in Australian prisons is not consistent across states, but Butler and colleagues (Butler, Richters, Yap, \& Donovan, 2013) reported that condoms were more likely to be used in prisons where policies allowed condoms to be freely available. As the authors noted, this may be hardly surprising; however, it demonstrates that where healthy choices are easy to make, it results in better health choices.

At the macro-level level, it is unrealistic to suggest that the prison setting with its limited resources and capacity can address the issue of poor prisoner health in isolation. Certainly prisons have a contribution to make, but they are only one component in a very complex jigsaw. One major way in which the multifaceted health and social issues surrounding offenders' lives will be resolved is when the unequal distribution of power in society is redistributed and wider social inequalities (e.g. poverty, unemployment) are addressed through macro-policy interventions. This has been reiterated by several other scholars, including Link and Phelan who have consistently argued that societal interventions are needed to produce major health benefits for populations (Link \& Phelan, 2002; Phelan, Link, 
\& Tehranifar, 2010). Their theory of fundamental causes is particularly apt when considering the health of prison populations. Indeed, St Leger (1997, p.101) suggests that when adopting a healthy setting (i.e. prison) there is a requirement to always stay with "the big picture". If released prisoners, for instance, are to refrain from re-engaging with drugs and find secure accommodation and employment then this is ultimately contingent upon effective social policy (Knepper, 2007). Dooris $(2007,2009)$, therefore, encourages advocates and public health professionals within settings to 'connect upwards' to ensure that broader political, economic and social factors are being addressed through political advocacy:

"Connecting upwards: A focus on the importance of settings programmes and initiatives working upwards, using advocacy and mediation to ensure action on the underlying determinants of health that may lie outside of their boundaries or immediate remit." (Dooris, 2007, p.139)

Outcomes which may demonstrate progress at an institutional level in terms of building healthy public policy may include:

- Prisons operating at their correct occupational levels;

- Appropriate staff-prisoner ratios;

- Prisoners having adequate time out of their cell;

- Meaningful occupation provided in prison that has application to employment postrelease;

- All prisoners being allocated a personal officer for pastoral support;

- Prison catering that meets nutritional standards;

- Sufficient contact with family.

At a macro-level, positive outcomes include: 
- An increased number of prisoners finding suitable accommodation on release;

- Prisoners gaining employment, education and training on opportunities in the community on their release;

- Reduced re-offending.

\section{Creating supportive environments}

A focus on creating supportive environments emphasises the importance of 'place' and shows how this is inextricably bound to health. Creating healthier prisons requires establishing prison environments that address the physical and social environments of the setting (Ramaswamy \& Freudenberg, 2007) and this includes considering architecture, prison policies, structures, prisoner-staff relationships and how these impact on individuals.

Two short examples show how the prison environment can influence health. First, prison overcrowding has both direct and indirect health outcomes (Ross, 2013). Disease transmission, for example, may be a direct effect but issues such as increased violence and prisoner unrest may also be a secondary adverse health outcome. Second, evidence shows that a prisoner's mental health is often contingent on regular family visits (Woodall, Dixey, Green, \& Newell, 2009). However, prison visits have generally declined over the past number of years (Broadhead, 2002; Salmon, 2005) and one explanation for this is that families entering prison can be treated unsympathetically by staff (Broadhead, 2002).

Selected outcomes that demonstrate positive health outcomes through addressing the prison environment include:

- Reduced overcrowding;

- Reduced violence; 
- Increased opportunities for meaningful occupation;

- Improved access to prison facilities (e.g. library, gymnasium)

- Preserved or improved family bonds;

- Improved prisoner - prison staff relationships;

- Better access to services.

\section{Strengthening community action}

Strengthening community action is defined in the Ottawa Charter as:

“...effective community action in setting priorities, making decisions, planning

strategies and implementing them to achieve better health. At the heart of this process

is the empowerment of communities, their ownership and control of their own

endeavours and destinies."(World Health Organization, 1986, p.iv)

Whilst empowering prisoners has never been an accepted pursuit in prison systems, even regarded as "morally questionable and politically dangerous"(The Aldridge Foundation \& Johnson, 2008, p.2), there is a growing recognition that contemporary prisons should be “supportive and empowering”(de Viggiani, Orme, Powell, \& Salmon, 2005, p.918). One example now commonly seen in prisons in England and Wales is the formation of prison councils to provide prisoners with democratic participation in prison life (Edgar, Jacobson, \& Biggar, 2011). These councils allow prison representatives to comment and shape policy and practices in the prison as well as suggesting recommendations for action (Solomon \& Edgar, 2004). Moreover, in recent times formal peer interventions have also become an integral feature of prison life and have continued to be driven, in part, by an active citizenship in prisons agenda (Edgar, et al., 2011). Evidence from international peer-based schemes show prisoners feeling able to discuss issues and be listened to and leading to improvements in prison culture (South et al., Forthcoming), which in turn creates more supportive 
environments. This harnesses the mutual support often naturally and informally developed between prisoners and further mitigates the development of hostile, bullying cultures which are so detrimental to health and wellbeing.

There are clear benefits when prisoners are able to participate and articulate their views; most notably, it can improve prisoners' self-esteem, improve the running of institutions and can improve staff - prisoner relationships (Solomon \& Edgar, 2004). Despite this, Levenson and Farrant (2002) note that participation is rarely intrinsic to prison cultures. Indeed, where prisoner involvement has emerged it is often sporadic and uneven and not consistent across the prison estate (Solomon, 2004; Solomon \& Edgar, 2004).

Selected outcomes that demonstrate strengthened community action in a prison setting may include:

- Prisoners' active involvement in institutional planning and strategy development;

- Reduced demands on prison staff as a result of a cadre of trained prison peer-workers;

- Improved prison ethos and culture leading to increased wellbeing, reduced stress for both inmates and staff, reduced violence.

\section{Developing personal skills}

The acquisition of personal skills is imperative for people to have control over their health, and this applies equally to prisoners. The development of personal skills conceivably constitutes a myriad of possibilities, but centres on the need to provide information and education for health, enhance life skills and influence health beliefs and values (Dixey, Cross, Foster, \& Woodall, 2013). Many interventions under the rubric of developing personal skills in prison have adopted a harm-reduction or risk-reduction philosophy using educational 
approaches. This philosophy aims to prevent or reduce negative health effects associated with certain types of behaviour (WHO, 2005). For example, a harm-reduction programme for women offenders in the US (Lehma, 2001), showed positive results in terms of improvements in knowledge and self-efficacy of participants in relation to the prevention of hepatitis and sexually transmitted infection. However, personal skills may also include providing practical skills training in life and social skills, such as parenting courses, like those described by Jarvis et al. (2004). Peer interventions in the prison settings also show promising results in developing prisoners' personal skills, including improvements in prisoners' knowledge of HIV (Bryan, Robbins, Ruiz, \& O'Neill, 2006; Collica, 2002; Ross, Harzke, Scott, McCann, \& Kelley, 2006; Scott, Harzke, Mizwa, Pugh, \& Ross, 2004) and uptake of HIV testing (Zack, Smith, Andrews, \& May, 2013), knowledge of sexually transmitted infections (Sifunda et al., 2008), beliefs, intentions and reported increases in condom use (Bryan, et al., 2006; Grinstead, Zack, Faigeles, Grossman, \& Blea, 1999; Magura, Kang, \& Shapiro, 1994) and increased inclination to practice safer drug using behaviours (Collica, 2002).

Although not exhaustive, outcomes that demonstrate changes to prisoners' personal skills at an individual level include:

- Improved knowledge and awareness;

- Changes in attitudes and beliefs;

- Improved self-efficacy;

- Communication and listening skills;

- Behavioural intentions;

- Reductions in risk behaviour.

System level outcomes may include: 
- Reduced transmission rates;

- Greater uptake of services.

\section{Reorienting health services}

The final area addressed by the Ottawa Charter is that health care services need to consider their health promotion potential and to embrace preventive approaches as well as the usual curative emphasis. Health services should not merely be seen as the place to go when someone is ill or has a health problem, but rather, as a place where they also go to become more well and to get advice on staying healthy. Freudenberg's (2001) review of the effect of good health promotion practices within US prisons shows that it can impact positively on the health of communities, particularly those poorer urban communities from which the majority of prisoners are drawn.

Health services have reoriented to some extent in primary health care on the 'outside' but this shift may not have fully permeated the prison health care service yet. Thus Whitehead (2006, p.123) suggested that prison nurses, "must first embrace the radical health promotion reforms that are emerging from the current literature", if they are to keep up with contemporary needs and a newer ethos. Meanwhile Awofeso (2005) has suggested that prison health care could be made more efficient by focusing on health promotion, including more preventive services and restructuring staffing. Back in 1996, Squires (1996) argued that the problem in the UK was more than simply who commissioned prison health services, and that non-health professional and agencies outside prisons needed to be included in order to change institutional cultures both within health services and the prison. 
A further challenge under this area of action is to educate people to use health services appropriately and in a timely fashion. As the majority of prisoners globally are men, and much is known about men's health care-seeking behaviours, (for instance, White and Johnson (2000) explore men's delay in seeking help for chest pain, and Buckley and O’Tuoma (2010) describe Irish men's behaviours as consumers of health care), there is much that could be achieved in terms of health education and patient education for prisoners so that they know how and when to access appropriate health care both inside prison and upon release.

Outcomes that would demonstrate a reorientation of health services would include:

- More emphasis on positive health within prison health care

- A greater understanding of preventive approaches among health care staff

- Better understanding of signs and symptoms among prisoners and thus earlier help seeking

- Development of a socio-ecological model of health promotion as opposed to one focussed on individual lifestyle and behaviour change alone.

\section{Moving beyond the Ottawa Charter}

Whilst the Ottawa Charter remains the foundation for health promotion, it is more than 25 years since it was written. Health promoters were heartened by the WHO's Commission on the Social Determinants of Health (Marmot, Friel, Bell, Houweling, \& Taylor, 2008) which quite rightly turned a focus on the 'causes of the causes', something that health promotion has long highlighted. It could be argued that the WHO's Commission on the Social Determinants of Health shows some continuity with the biomedical approach to disease and ill-health, 
showing the continued dominance of the latter in the discourse. Certainly in various national government reports and those from the UN concerning determinants there is a real emphasis on the proximate causes of ill health, those related to individual lifestyles, 'choices' and 'risk factors'. Thus the 'causes of the causes' discourse, resonating with Link and Phelan's theory of fundamental causes, has perhaps become rhetorical rather than being revolutionary.

Emancipatory health promotion has citizenship and personal agency at its heart, enabling individuals and communities to change the material circumstances in which they live, and this relates back to the original and much-quoted definition of health promotion used in the Ottawa Charter. Emancipatory health promotion thus prioritises the social determination of health, not simply the social determinants of health. However, there seems to be a great disjuncture between the ideas embedded within emancipatory health promotion, with its emphasis on empowerment and people taking control of the factors determining their health, and the reality on the ground facing those experiencing health inequalities, especially those imprisoned. Health inequalities mean that people bear the scars of social conditions in their bodies and minds, as demonstrated by data showing higher rates of a range of disease amongst those from 'lower' social classes. 'Embodiment' is an outward show of power differentials, though those scars are often carried internally, in the form of social alienation, depression, despair, low expectations and criminality. As noted, offenders are drawn disproportionately from more deprived social strata. It would be naïve to suggest that prisons can prioritise empowerment of prisoners, as the main purpose of prison is punishment through loss of liberty and to keep the public safe. However, if prisons are to prevent reoffending, and also to address health, there needs to be a push to see how far they can take on more of the key principles of 'emancipatory health promotion'. 
However, as Woodall et al (2013, p.7) say in a paper that explores how key elements of health promotion discourse - choice, control and implicitly, empowerment - are contradictory and puzzling in the context of health promoting prison settings: "Empowerment is central to becoming the author of one's own life and being able to control the forces that exist in pathogenic and criminogenic environments. The paradox is that prisons are by their nature disempowering yet are tasked with creating more empowered individuals capable of taking control of their lives on release." In other words, as most prisoners are expected to be released at some point and to not only move away from their previously criminal life but also to take control of the pathogenic circumstances which caused it, they need to be equipped to exercise some agency, control and choice. However, these opportunities to exercise agency and control will be constrained whilst 'inside'. Prisoners' lives have often been systematically regimented and controlled (by the prison regime) that their ability to cope with choices and responsibilities in the community is diminished. How, therefore, can health be socially determined by prisoners and other offenders, given that the social determination of health requires citizens to have a voice, power and skills? Can prison settings be 'salutogenic'? This is the real challenge to 'prison health' in the twenty first century.

The concept of salutogenesis has perhaps been more well developed in the Scandinavian countries than elsewhere, and Servan (2012), discussing successful reintegration of women prisoners in Norway, has argued that "This approach (salutogenesis) provides insights that more traditional studies on recidivism and desistance is not able to give." Allies in related areas such as design and architecture are also calling to move health improvement further up the prison agenda: "All new prison design policies should include health impact assessments, and prison design should be modified accordingly" (Awofeso, 2011). The Halden prison in Norway is perhaps the most well-known example of a prison designed to be more humane, 
with health improvement an explicit goal. There are an increasing number of examples of community-based health promotion initiatives that have been adopted within prison settings. These should be welcomed as they often provide prisoners with the responsibility that underpins meaningful citizenship and successful rehabilitation back into society. Indeed, we can think of people in prison in two discrete ways - as 'citizens in prison' or as prisoners (Svensson, 1996). A contemporary prison system, embracing the values of health promotion, should embrace the former rather than the latter and equip individuals with the necessary skills to reintegrate successfully back into society. Prisoners often wish to take control and make choices which are beneficial for their own health and rehabilitation and yet systemic barriers can inhibit such decisions. Conditions in the prison setting must empower prisoners through offering responsibilities, choice and control over their long-term rehabilitation process rather than deskilling and disempowering those who are imprisoned.

\section{Conclusions}

Our philosophical stance on 'prison health' is embedded in a social model that moves away from a reductionist, biomedical focus to a viewpoint whereby health is influenced by a range of factors that can be structural and environmental in nature. This position poses challenges to those working in prison health services as it suggests that prisoners' health is influenced by countless factors which lie outside the health workers' control. However, we argue that health is the concern of all those working within the prison, and not only that of the dedicated 'health' staff. Indeed, the essence of a healthy setting is that every aspect of that institution is carefully scrutinised in order to maximise its health potential. 
It makes sense to health promoters to use the Ottawa Charter to frame an agenda for improvement in prison health, as the Charter is widely recognised to be as useful and relevant as a basis for public health and health promotion in the twenty first century as it was when first developed (Nutbeam, 2008; Sparks, 2011). By drawing on the action areas of the Ottawa Charter (World Health Organization, 1986) this paper has outlined a feasible framework to develop policy and practice for the health promoting prison that rests on a social model. The five action areas are overlapping and inter-related and should not be seen as mutually exclusive. The paper attempts to outline what outcomes of success within a social model of prisoner health may constitute, although we acknowledge that these are by no means exhaustive and that guidance has not been offered on how these outcomes may be measured. We also suggest that there are contradictions within emancipatory health promotion especially in relation to offender populations. It is difficult to see how poorer communities can be fully empowered, with power structures subverted, let alone how incarcerated groups could be. Prison health promotion thus needs to be realistic in terms of what it can achieve but what it must do is take into account the socioeconomic conditions, the real material situation, and the structures of power in which criminogenic behaviour is generated.

Developing prison based public health and health promotion is not easy and those who are currently working to deliver successful interventions in this setting are doing so within an environment of paradoxical values and philosophies. Approaches to health, particularly health promotion, have developed considerably within prisons but there is still a way to go. We hope that the framework presented here offers those working in the field an opportunity to reflect on current practice and to consider prisoners' health in a more holistic sense that recognises that health is more than just the absence of disease. 


\section{References}

Anno, J. (2004). Prison health services: an overview. Journal of Correctional Heathcare, 10(3), 287-301.

Anon. (2008). Advocates working to improve prison health in the Americas. The Nation's Health, 38(1), 4.

Awofeso, N. (2005). Making prison health care more efficient. British Medical Journal, $331(7511), 248-249$.

Awofeso, N. (2010). Prisons as social determinants of hepatitis C virus and tuberculosis infections. Public Health Reports, 125, 25-33.

Awofeso, N. (2011). Disciplinary architecture: prison design and prisoners' health. Hektoen International: A Journal of Medical Humanities, 1(3).

Baybutt, M., Hayton, P., \& Dooris, M. (2010). Prisons in England and Wales: an important public health opportunity? In J. Douglas, S. Earle, S. Handsley, L. Jones, C. Lloyd \& S. Spurr (Eds.), A reader in promoting public health. Challenge and controversy (2nd ed., pp. 134-142). Milton Keynes: Open University Press.

Belcher, J. M., Butler, T., Richmond, R. L., Wodak, A. D., \& Wilhelm, K. (2006). Smoking and its correlates in an Australian prisoner population. Drug and Alcohol Review, 25(4), 343-348.

Bhui, H. S. (2009). Prisons and race equality. In H. S. Bhui (Ed.), Race and criminal justice (pp. 83-101). London: Sage.

Bosworth, M. (2002). The US federal prison system. Thousand Oaks: Sage.

Bosworth, M., Campbell, D., Demby, B., Ferranti, S. M., \& Santos, M. (2005). Doing prison research: views from inside. Qualitative Inquiry, 11(2), 249-264. 
Broadhead, J. (2002). Visitors welcome - or are they. The New Law Journal, 152(5), 70147015.

Bryan, A., Robbins, R. N., Ruiz, M. S., \& O'Neill, D. (2006). Effectiveness of an HIV prevention intervention in prison among African Americans, Hispanics, and Caucasians. Health Education \& Behavior, 33(2), 154-177.

Buckley, J., \& O'Tuoma, S. (2010). 'I send the wife to the doctor' - men's behaviour as health consumers. International Journal of Consumer Studies, 34(5), 587-595.

Butler, T., Richters, J., Yap, L., \& Donovan, B. (2013). Condoms for prisoners: no evidence that they increase sex in prison, but they increase safe sex. Sexually Transmitted Infections.

Caraher, M., Dixon, P., Hayton, P., Carr-Hill, R., McGough, H., \& Bird, L. (2002). Are health-promoting prisons an impossibility? Lessons from England and Wales. Health Education, 102(5), 219-229.

Collica, K. (2002). Levels of knowledge and risk perceptions about HIV/AIDS among female inmates in New York State: can prison-based HIV programs set the stage for behavior change? The Prison Journal, 82(1), 101-124.

de Viggiani, N. (2006). A new approach to prison public health? Challenging and advancing the agenda for prison health. Critical Public Health, 16(4), 307-316.

de Viggiani, N. (2007). Unhealthy prisons: exploring structural determinants of prison health. Sociology of Health \& Illness, 29(1), 115-135.

de Viggiani, N., Orme, J., Powell, J., \& Salmon, D. (2005). New arrangements for prison health care provide an opportunity and a challenge for primary care trusts. British Medical Journal, 330(7497), 918.

Department of Health. (2002). Health promoting prisons: a shared approach. London: Crown. 
Department of Health. (2009). Improving health, supporting justice: the national delivery plan of the health and criminal justice programme board. London: Department of Health.

Dixey, R., Cross, R., Foster, S., \& Woodall, J. (2013). Foundations of health promotion. In R. Dixey (Ed.), Health promotion: global principles and practice. London: CABI.

Dooris, M. (2007). Healthy settings: past, present and future. Unpublished PhD thesis. PhD, Deakin University, Victoria.

Dooris, M. (2009). Holistic and sustainable health improvement: the contribution of the settings-based approach to health promotion. Perspectives in Public Health, 129(1), 29-36.

Edgar, K., Jacobson, J., \& Biggar, K. (2011). Time well spent: a practical guide to active citizenship and volunteering in prison. London: Prison Reform Trust.

Edgar, K., O'Donnell, I., \& Martin, C. (2003). Prison violence. The dynamics of conflict, fear and power. Cullompton: Willan Publishing.

Fazel, S., \& Danesh, J. (2002). Serious mental disorder in 23,000 prisoners: a systematic review of 62 surveys. The Lancet, 359(9306), 545-550.

Freudenberg, N. (2001). Jails, prisons, and the health of urban populations: a review of the impact of the correctional system on community health. Journal of Urban Health, $78(2), 214-235$.

Gatherer, A., Møller, L., \& Hayton, P. (2005). The World Health Organization European health in prisons project after 10 years: persistent barriers and achievements. American Journal of Public Health, 95(10), 1696-1700.

Gear, S. (2007). Behind the bars of masculinity: male rape and homophobia in and about South African men's prisons. Sexualities, 10(2), 209-227. 
Goffman, E. (1968). Asylums: essays on the social situation of mental patients.

Harmondsworth: Penguin.

Grinstead, O., Zack, B., Faigeles, B., Grossman, N., \& Blea, L. (1999). Reducing postrelease HIV risk among male prison inmates. A peer led intervention. Criminal Justice and Behavior, 26(4), 453-465.

Hayton, P. (2007). Protecting and promoting health in prisons: a settings approach. In L. Møller, H. Stöver, R. Jürgens, A. Gatherer \& H. Nikogosian (Eds.), Health in prisons (pp. 15-20). Copenhagen: WHO.

Hensley, C. (2000). Attitudes toward homosexuality in a male and female prison: an exploratory study. The Prison Journal, 80(4), 434-441

Herbert, K., Plugge, E., Foster, C., \& Doll, H. (2012). Prevalence of risk factors for noncommunicable diseases in prison populations worldwide: a systematic review. The Lancet, 379(9830), 1975-1982.

HM Prison Service. (2003). Prison Service Order (PSO) 3200 on health promotion. London: HM Prison Service.

HMIP. (1996). Patient or prisoner? A new strategy for health care in prisons. London: Home Office.

Ireland, C. A., \& Ireland, J. L. (2000). Descriptive analysis of the nature and extent of bullying behavior in a maximum-security prison. Aggressive Behavior, 26(3), 213 223.

Ireland, J. L. (2002). Bullying among prisoners: evidence, research and intervention strategies. London: Routledge.

Jacobs, J. (1977). Stateville. Chicago: University of Chicago Press.

Jarvis, J., Graham, S., Hamilton, P., \& Tyler, D. (2004). The role of parenting classes for young fathers in prison: a case study. Probation Journal, 51(1), 21-33. 
Kemm, J. (2001). Health impact assessment: a tool for healthy public policy. Health Promotion International, 16(1), 79-85.

Kickbusch, I. (1986). Issues in health promotion. Health Promotion, 1(4), 437-442.

Kickbusch, I. (2003). The contribution of the World Health Organization to a new public health and health promotion. American Journal of Public Health, 93(3), 383-388.

Knepper, P. (2007). Criminology and social policy. London: Sage.

Lahm, K. F. (2009). Inmate assaults on prison staff: a multilevel examination of an overlooked form of prison violence. The Prison Journal, 89(2), 131-150.

Lehma, C. (2001). Description and evaluation of a health education program for women offenders. The ABNF Journal, 12(6), 124-129.

Lester, C., Hamilton-Kirkwood, L., \& Jones, N. K. (2003). Health indicators in a prison population: asking prisoners. Health Education Journal, 62(4), 341-349.

Levenson, J., \& Farrant, F. (2002). Unlocking potential: active citizenship and volunteering by prisoners. Probation Journal, 49(3), 195-204.

Levy, M. (2005). Prisoner health care provision: reflections from Australia. International Journal of Prisoner Health, 1(1), 65-73.

Lincoln, T., Miles, J. R., \& Scheibel, S. (2007). Community health and public health collaborations. In R. B. Greifinger, J. Bick \& J. Goldenson (Eds.), Public health behind bars. From prisons to communities (pp. 508-534). New York: Springer.

Lines, R. (2006). From equivalence of standards to equivalence of objectives: the entitlement of prisoners to health care standards higher than those outside prisons. International Journal of Prisoner Health, 2(4), 269-280.

Link, B. G., \& Phelan, J. C. (2002). McKeown and the idea that social conditions are fundamental causes of disease. American Journal of Public Health, 92(5), 730-732. 
Magura, S., Kang, S. Y., \& Shapiro, J. L. (1994). Outcomes of intensive AIDS education for male adolescent drug users in jail. Journal of Adolescent Health, 15(6), 457-463.

Marmot, M., Friel, S., Bell, R., Houweling, T. A., \& Taylor, S. (2008). Closing the gap in a generation: health equity through action on the social determinants of health. The Lancet, 372(9650), 1661-1669.

Marquart, J. W., Merianos, D. E., Hebert, J. L., \& Carroll, L. (1997). Health condition and prisoners: A review of research and emerging areas of inquiry. The Prison Journal, 77(2), 184-208.

Milio, N. (1986). Promoting health through public policy. Ottawa: Canadian Public Health Association.

Møller, L., Gatherer, A., \& Dara, M. (2009). Barriers to implementation of effective tuberculosis control in prisons. Public Health, 123(6), 419-421.

Møller, L., Stöver, H., Jürgens, R., Gatherer, A., \& Nikogosian, H. (2007). Health in prisons. Copenhagen: WHO.

Morris, T., \& Morris, P. (1963). Pentonville: a sociological study of an English prison London: Routledge.

Newton, C. (1994). Gender theory and prison sociology: using theories of masculinities to interpret the sociology of prisons for men. The Howard Journal of Criminal Justice, 33(3), 193-202.

Niveau, G. (2007). Relevance and limits of the principle of "equivalence of care" in prison medicine. Journal of Medical Ethics, 33(10), 610-613.

Nutbeam, D. (1998). Evaluating health promotion—progress, problems and solutions. Health Promotion International, 13(1), 27-44.

Nutbeam, D. (2008). What would the Ottawa Charter look like if it were written today? Critical Public Health, 18(4), 435-441. 
Phelan, J. C., Link, B. G., \& Tehranifar, P. (2010). Social conditions as fundamental causes of health inequalities theory, evidence, and policy implications. Journal of Health and Social Behavior, 51(1 suppl), S28-S40.

Plugge, E., Douglas, N., \& Fitzpatrick, R. (2006). The health of women in prison. Oxford: Department of Public Health, University of Oxford.

Prison Reform Trust. (2009). Bromley briefings. Prison factfile. London: Prison Reform Trust.

Ramaswamy, M., \& Freudenberg, N. (2007). Health promotion in jails and prisons: an alternative paradigm for correctional health services. In R. B. Greifinger, J. Bick \& J. Goldenson (Eds.), Public health behind bars. From prisons to communities (pp. 229248). New York: Springer.

Reyes, H. (2001). Health and human rights in prison. In P. Bollini (Ed.), HIV in prisons. Copenhagen: WHO.

Robertson, S. (2006). 'Not living life in too much of an excess': lay men understanding health and well-being. Health, 10(2), 175-189.

Ross, M. (2013). Health and health promotion in prisons. Oxon: Routledge.

Ross, M., Harzke, A. J., Scott, D. P., McCann, K., \& Kelley, M. (2006). Outcomes of project wall talk: an HIV/AIDS peer education program implemented within the Texas state prison system. AIDS Education and Prevention, 18(6), 504-517.

Rutherford, M., \& Duggan, S. (2009). Meeting complex health needs in prison. Public Health, 123(6), 415-418.

Rütten, A., \& Gelius, P. (2011). The interplay of structure and agency in health promotion: integrating a concept of structural change and the policy dimension into a multi-level model and applying it to health promotion principles and practice. Social Science \& Medicine, 73(7), 953-959. 
Salmon, S. (2005). Prisoners' children matter. Prison Service Journal, 159, 16-19.

Scott, D. P., Harzke, A. J., Mizwa, M., B, Pugh, M., \& Ross, M. W. (2004). Evaluation of an HIV peer education program in Texas prisons. Journal of Correctional Health Care, 10(2), 151-173.

Senior, J., \& Shaw, J. (2007). Prison healthcare. In Y. Jewkes (Ed.), Handbook on prisons (pp. 377-398). Cullompton: Willan Publishing.

Servan, A. K. (2012). Societal reintegration experiences of women with judicial sentences participating in a re-entry program in Norway-from wrongdoings to wellbeing. MSc, University of Bergen.

Shalev, S. (2008). A sourcebook on solitary confinement. London: Mannheim Centre for Criminology.

Sifunda, S., Reddy, P. S., Braithwaite, R., Stephens, T., Bhengu, S., Ruiter, R. A., \& van den Borne, B. (2008). The Effectiveness of a Peer-Led HIV/AIDS and STI Health Education Intervention for Prison Inmates in South Africa. Health Education \& Behavior, 35(4), 494-508.

Sim, J. (1990). Medical power in prisons. Milton Keynes: Open University Press.

Sim, J. (2002). The future of prison health care: a critical analysis. Critical Social Policy, 22(2), 300-323.

Smith, C. (2000). Healthy prisons: a contradiction in terms? The Howard Journal of Criminal Justice, 39(4), 339-353.

Smith, C. (2002). Punishment and pleasure: women, food and the imprisoned body. Sociological Review, 50(2), 197-211.

Social Exclusion Unit. (2002). Reducing re-offending by ex-prisoners. London: Crown.

Solomon, E. (2004). Criminals or citizens? Prisoner councils and rehabilitation. Criminal Justice Matters, 56(1), 24-25. 
Solomon, E., \& Edgar, K. (2004). Having their say: the work of prisoner councils. London: Prison Reform Trust.

South, J., Bagnall, A., Hulme, C., Woodall, J., Longo, R., Dixey, R., . . Wright, J. (Forthcoming). A systematic review of the effectiveness and cost-effectiveness of peer-based interventions to maintain and improve offender health in prison settings. Report for the National Institute for Health Research (NIHR) Health Services and Delivery Research (NIHR HS\&DR) programme Project: 10/2002/13. .

Spalek, B. (2002). Islam, crime and criminal justice Cullompton: Willan Publishing. Sparks, M. (2011). Building healthy public policy: don't believe the misdirection. Health Promotion International, 26(3), 259-262.

Spencer, J., Haslewood-Pocsik, I., \& Smith, E. (2009). 'Trying to get it right': what prison staff say about implementing race relations policy. Criminology and Criminal Justice, 9(2), 187-206

Squires, N. (1996). Promoting health in prisons. British Medical Journal, 313(7066), 1161. Squires, P., \& Measor, L. (2001). 'Breaking in’: partnership working, health promotion and prison walls. In D. Taylor (Ed.), Breaking down barriers. Reviewing partnership practice (pp. 124-164). Brighton: University of Brighton.

St Leger, L. (1997). Health promoting settings: form Ottawa to Jakarta. Health Promotion International, 12(2), 99-101.

Stewart, D. (2008). The problems and needs of newly sentenced prisoners: results from a national survey. London: Ministry of Justice.

Svensson, S. (1996). Imprisonment - a matter of letting people live or stay alive? Some reasoning from a Swedish point of view. Journal of Correctional Education, 47(2), $69-72$ 
Sykes, G. M. (1958). The society of captives: a study of a maximum security prison. New Jersey: Princeton University Press.

The Aldridge Foundation, \& Johnson, M. (2008). The user voice of the criminal justice system. London: The Aldridge Foundation.

The Centre for Social Justice. (2009). Breakthrough Britain: locked up potential. London: The Centre for Social Justice.

Visher, C. A., \& Travis, J. (2003). Transitions from prison to community: understanding Individual Pathways. Annual Review of Sociology, 29, 89-113.

Warwick-Booth, L., Cross, R., \& Lowcock, D. (2012). Contemporary health studies: an introduction. Cambridge: Polity Press.

White, A., \& Johnson, M. (2000). Men making sense of their chest pain: niggles, doubts and denials. Journal of Clinical Nursing, 9(4), 534-542.

Whitehead, D. (2006). The health promoting prison (HPP) and its imperative for nursing. International Journal of Nursing Studies, 43(1), 123-131.

WHO. (1986). Ottawa Charter for health promotion. Health Promotion, 1(4), iii - v. doi: 10.1093/heapro/1.4.405

WHO. (1998). Mental health promotion in prisons. Report on a WHO meeting. Copenhagen: WHO.

WHO. (2001a). HIV in prisons. A reader with particular relevance to the newly independent states. Geneva: WHO.

WHO. (2001b). Prisons, drugs and society. A consensus statement on principles, policies and practices. Geneva: WHO.

WHO. (2003). Promoting the health of young people in custody. Copenhagen: WHO.

WHO. (2005). Status paper on prisons, drugs and harm reduction. Geneva: WHO. 
WHO. (2007). Health in prisons. A WHO guide to the essentials in prison health. Copenhagen: WHO.

WHO. (2008). Background paper for Trenčín statement on prisons and mental health. Copenhagen: WHO.

Winterbauer, N. L., \& Diduk, R. M. (2013). The ten essential public health services model as a framework for correctional health care. Journal of Correctional Health Care, 19(1), 43-53.

Woodall, J. (2010a). Control and choice in three category-C English prisons: implications for the concept and practice of the health promoting prison. Unpublished PhD thesis. $\mathrm{PhD}$, Leeds Metropolitan University, Leeds.

Woodall, J. (2010b). Exploring concepts of health with male prisoners in three category-C English prisons. International Journal of Health Promotion and Education, 48(4), $115-122$.

Woodall, J. (2012). Social and environmental factors influencing in-prison drug use. Health Education, 1(112), 31-46.

Woodall, J., Dixey, R., Green, J., \& Newell, C. (2009). Healthier prisons: the role of a prison visitors' centre. International Journal of Health Promotion and Education, 47(1), 1218.

Woodall, J., Dixey, R., \& South, J. (2013). Control and choice in English prisons: developing health-promoting prisons. Health Promotion International, doi: 10.1093/heapro/dat1019.

Woodall, J., \& South, J. (2012). Health promoting prisons: dilemmas and challenges. In A. Scriven \& M. Hodgins (Eds.), Health promotion settings: principles and practice (pp. 170-186). London: Sage. 
World Health Organization. (1986). Ottawa Charter for health promotion. Health Promotion, 1(4), iii - v. doi: 10.1093/heapro/1.4.405

Zack, B., Smith, C., Andrews, M. C., \& May, J. P. (2013). Peer Health Education in Haiti's National Penitentiary The "Health through Walls" Experience. Journal of Correctional Health Care, 19(1), 65-68. 